Article

\title{
Correlation between Microstructural Evolution and Mechanical Properties of 2000 MPa Cold-Drawn Pearlitic Steel Wires during Galvanizing Simulated Annealing
}

\author{
Xiuyu Lu \\ Wuhan Branch of Baosteel Central Research Institute, Wuhan 430080, China; E85345@baosteel.com; \\ Tel.: +027-8648-7672
}

Received: 26 January 2019; Accepted: 11 March 2019; Published: 14 March 2019

\begin{abstract}
In the present experiment, hot-dip galvanizing simulated annealing of $2000 \mathrm{MPa}$ cold-drawn pearlitic steel wires was carried out at $450{ }^{\circ} \mathrm{C}$. The effects of microstructural evolution on the mechanical properties of the as-prepared wires were analyzed through scanning electron microscopy (SEM), transmission electron microscopy (TEM), tensile test, torsion test, and Vickers hardness test. In addition, the relationship between torsion laps and microstructural evolution of cold-drawn pearlitic steel wires was investigated in detail. It was found that the torsional performance of the wires deteriorated after annealing at $450{ }^{\circ} \mathrm{C}$ for $2-5 \mathrm{~min}$, and the corresponding microstructural evolution was accompanied by the partial degradation of lamellar pearlites due to the diffusion and dislocation pinning of dissolved carbon atoms in ferrites, and it is not feasible to achieve the matching of strength and torsion laps by prolonging the holding time. The deterioration in torsional performance can be attributed to the microstructural difference between the surface and the center of the annealed wires. When the proportion of non-lamellar structure between the surface and the center in each specimen exceeded $8 \%$, the microhardness difference was found to be greater than $40 \mathrm{HV}$ and the torsion lap was less than 3 circles.
\end{abstract}

Keywords: $2000 \mathrm{MPa}$; cold-drawn pearlitic steel wires; pearlite degradation; torsion laps

\section{Introduction}

Due to their excellent strength and ductility, galvanized steel wires are the core materials of large steel bridge cables [1-3]. The general manufacturing process of galvanized steel wires involves the following procedure: pearlitic wire rods are first drawn into wires through multiple passes and subsequently subjected to hot-dip galvanization for $\sim 1 \mathrm{~min}$ to improve their anti-corrosion properties [4-6]. However, the torsional performance of pearlitic steel wires deteriorates significantly during hot-dip galvanization [7]. Therefore, it is important to understand the effects of hot-dip galvanization on the microstructural properties of high-strength pearlite steel wires.

The relationship between microstructural evolution and the strength of cold-drawn pearlitic steel wires during hot-dip galvanization has been explored in some studies [4,8-11]. During annealing, the degradation of lamellar pearlites is accompanied by cementite dissolution due to the diffusion of carbon atoms. The interfacial free energy mechanism (proposed by Languillaume et al. [9]) and the carbon atom-dislocation interaction mechanism (reported by Gridnev et al. [10]) are often used to explain the process of cementite dissolution. According to Watte et al. [11], the energy state near dislocations is generally found to be lower than that of other regions; therefore, carbon atoms cross the energy barrier after gaining energy during annealing and gather around dislocations in ferrites. 
Torsion tests are commonly employed to assess the torsional ductility of pearlitic steel wires, and thus the decrease in torsion lap during hot-dip galvanization restricts the further improvement in their strengths [5,12-14]. Previous studies have reported the deterioration in torsional properties of cold-drawn steel wires during annealing; however, the reasons for torsion delamination are still undetermined. The occurrence of torsion delamination in cold-drawn steel wire is almost inevitable during the annealing process, in which there is almost no change in its overall microstructure $[15,16]$. Torsion laps of cold-drawn steel wires are affected by several factors, including surface cracks [17], abnormally large cementite [18], as well asthede formation and spheroidization of lamellar cementites [5,14]. Zhou et al. [13] found that annealing treatment changed cementite structure from disordered to nanocrystalline state, and the recrystallized cementite impeded dislocation motion and broke up around high-density dislocation zones, resulting in micro-cracks during torsion tests. Tarui and Maruyama [15] showed that the carbon atoms in wires diffused strongly during the galvanization treatment. The carbon atoms locally saturated in the ferrite phase, and brittle stratification occurred when the carbon atom concentration difference in some regions exceeded approximately 1 at. $\%$.

In the present work, hot-dip galvanizing simulated annealing of $2000 \mathrm{MPa}$ cold-drawn pearlitic steel wires was performed at $450{ }^{\circ} \mathrm{C}$ for different time periods. The effects of the microstructural evolution on the mechanical properties of the as-prepared wires were investigated. In addition, reasons for the deterioration in torsional performance of the wires during annealing were revealed.

\section{Materials and Methods}

\subsection{Test Materials}

Hypereutectoid steel wires of diameter $6.9 \mathrm{~mm}$ were continuously drawn from Stelmor-cooled wire rods of diameter $14.0 \mathrm{~mm}$ (supplied by WISCO, Wuhan, China) at a drawing speed of $3.3 \times 10^{-2} \mathrm{~m} / \mathrm{s}$. The overall compression ratio and the maximum single-pass reduction rate during wire drawing were, respectively, $75.7 \%(\varepsilon=1.42)$ and $<19.7 \%$. The chemical composition of the wires is depicted in Table 1. The tensile strength and the torsion lap of the cold-drawn steel wires were $2095 \mathrm{MPa}$ and 17 circles, respectively.

Table 1. Chemical components of samples (wt. \%).

\begin{tabular}{ccccccc}
\hline $\mathbf{C}$ & $\mathbf{S i}$ & $\mathbf{M n}$ & $\mathbf{P}$ & $\mathbf{S}$ & $\mathbf{C u}$ & $\mathbf{C r}$ \\
\hline 0.97 & 1.05 & 0.65 & 0.008 & 0.006 & 0.20 & 0.30 \\
\hline
\end{tabular}

\subsection{Annealing Treatment}

In the actual hot-dip galvanizing process, cold-drawn steel wires are infiltrated in zinc solution at $450{ }^{\circ} \mathrm{C}$ for about $1 \mathrm{~min}$. In the current study, in order to simulate the hot-dip galvanizing process, the cold-drawn steel wires were first annealed at $450{ }^{\circ} \mathrm{C}$ in a MSRA-621 resistance furnace (Weier, Jiangsu, China) for different holding times $(0.5,1,2,3,5,15,30,60$, and $120 \mathrm{~min})$ and then cooled in air to room temperature.

\subsection{Mechanical Performance Test}

The tensile test was carried out in a CMT5105 universal testing machine (crosshead speed of $4 \mathrm{~mm} / \mathrm{min}, \mathrm{MTS}$, Jinan, China) at room temperature. Wires were cut into pieces of $350 \mathrm{~mm}$ length and used as the test specimens. Three experiments were executed for each sample.

Torsion laps were measured by a CTT1000 torsion tester (MTS, Jinan, China) at a speed of 30 $\mathrm{r} / \mathrm{min}$. The chuck spacing for all torsional specimens was set to $\sim 210 \mathrm{~mm}$. One of the ends of the wires was fixed, meanwhile the other end could be rotated, and five identical samples were tested under each condition. 
The microhardness test was performed in a Q60A+ Vickers hardness tester (Qness, Salzburg, Austria) under a load of $1000 \mathrm{~g}$ and a working time of $10 \mathrm{~s}$. Three cross sections were first taken for each sample. The measurement position was selected as two vertical lines passing through the geometric center of each cross section; therefore a total of six line segments were measured for each sample. The measurement interval was $0.5 \mathrm{~mm}$, and each line segment guaranteed 13 effective measuring points. In order to determine the microhardness fluctuation on the cross section of each sample, the difference between the maximum and the minimum values of each line segment was measured.

\subsection{Microstructure Observation}

Transmission electron microscopy (TEM; JEM 2000 EX, JEOL, Tokyo, Japan) was adopted to reveal the microstructures of the steel wires. TEM foils were obtained on transverse sections, and the observation areas were taken in the center. The TEM samples were prepared in a GATAN 691 precision ion polishing system.

The microscopic morphologies of the samples were observed by a scanning electron microscope (SEM; FEI Siron-400, Quanta, Portland, OR, USA). The SEM specimens were prepared by etching in $3 \%$ nitric acid-alcohol solution. The observation areas were the surface (distance from wire edge $<1.0$ $\mathrm{mm}$ ) and the center (distance from wire edge $>3.0 \mathrm{~mm}$ ).

The continuous lamellar structures of cementites in pearlites were effectively distinguished by SEM under a magnification of about 20,000 times. In order to obtain quantitative statistics on discontinuous lamellar pearlitic structures, discontinuous lamellar pearlite areas were first manually marked on the captured SEM images. The marked regions were quantitatively characterized by Analysis Pro 5 software (BAHENS, Shanghai, China, 2006) to obtain the proportion of discontinuous lamellar pearlitic structure. At least 20 images were captured in each region to ensure the accuracy of the data.

\section{Results and Discussion}

\subsection{Tensile Strength and Torsion Laps}

Figure 1a presents tensile strengths and torsion laps of the cold-drawn steel wires after annealing at $450{ }^{\circ} \mathrm{C}$. At the initial stage of annealing (0-5 min), the tensile strength values were maintained above $2000 \mathrm{MPa}$. The tensile strength reached the maximum value of $2105 \mathrm{MPa}$ (tensile fracture is shown in Figure 1b) after about 3 min annealing and then sharply decreased to below 2000 MPa when the holding time exceeded 5 min.
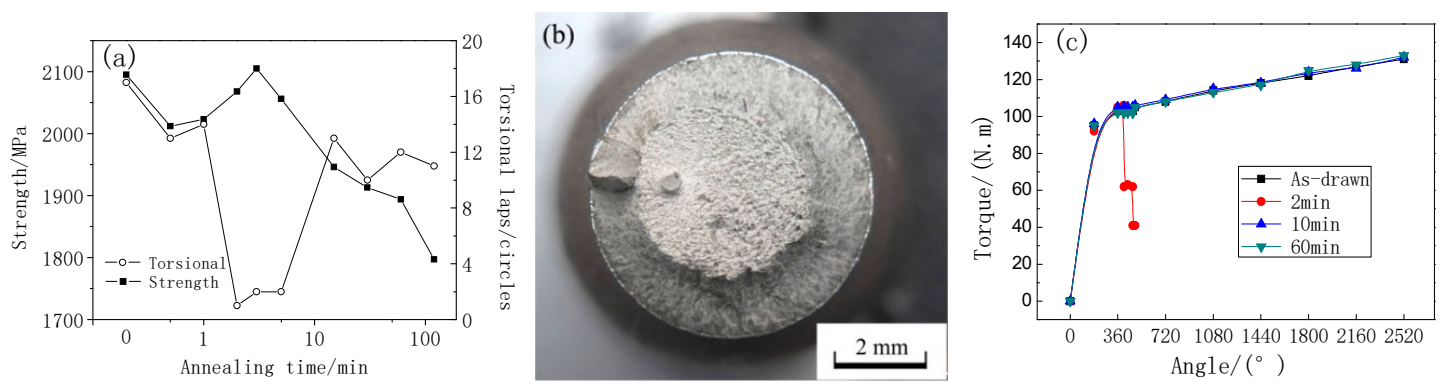

Figure 1. (a) Tensile strength and torsional laps and strength curves of steel wires after being held for different times at $450{ }^{\circ} \mathrm{C}$; (b) tensile fracture of wires annealed for $3 \mathrm{~min}$; and (c) curves of torque vs. torsion angle.

The torsional properties of steel wires were relatively stable, and the integrals of the mean values were taken for comparative analysis. The torsional stress curves of some wires are shown in Figure 1c. The torsion lap of the cold-drawn pearlitic steel wires was 17 circles; the corresponding torsional fracture was flat, and the microscopic morphologies of the samples mainly consisted of fine dimples (Figure 2a,c). With increasing holding time, the torsion lap first decreased and then increased. After 2-5 min of 
annealing, the torsion lap remained at less than three circles; the corresponding fracture was dominated by longitudinal brittle delamination and the microscopic morphologies of the wires were composed of cleavages (Figure 2b,d). When the holding time exceeded $10 \mathrm{~min}$, the torsion lap gradually increased to about 10 circles and remained stable, and the corresponding torsional fracture was found to be flat.
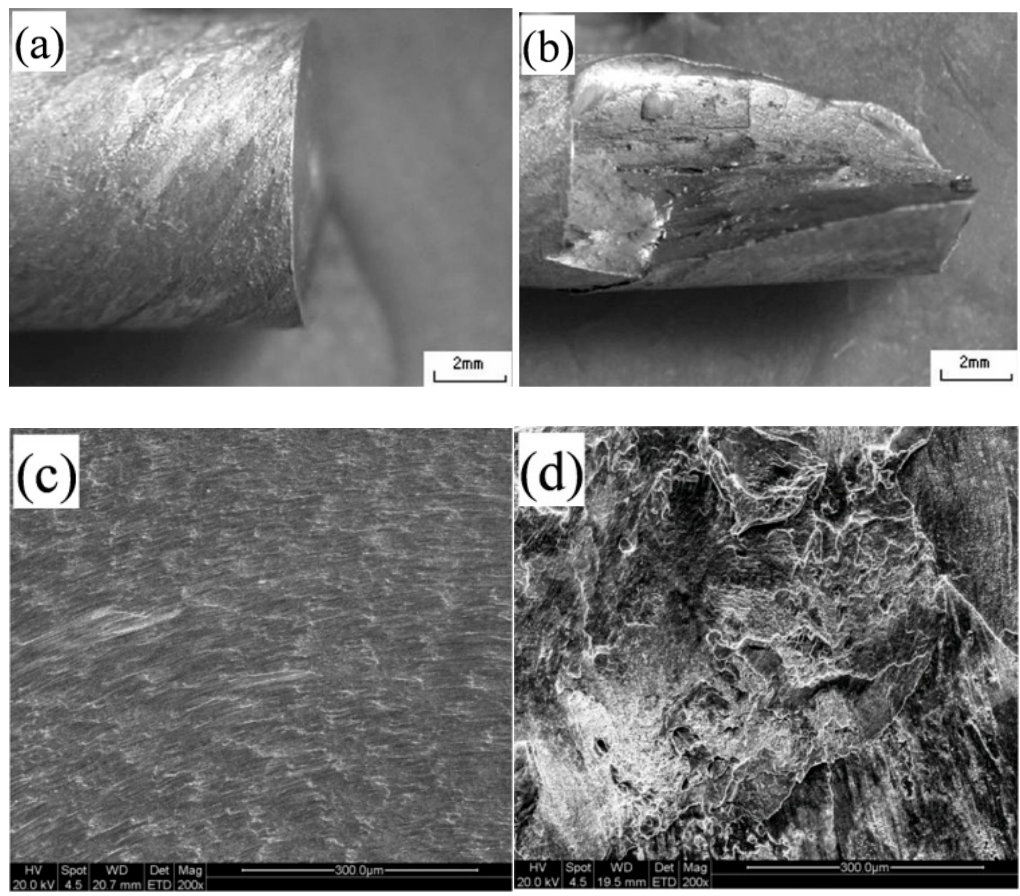

Figure 2. Torsional fracture morphology of the wires: (a,c) 17 circles, flat fracture; (b,d) 2 circles, stratified fracture.

\subsection{Microhardness}

Figure 3 displays the microhardness values of the wires for different annealing times. Figure 3a presents the mean microhardness values for the corresponding measuring points of six line segments at the cross sections. The microhardness values fluctuated at the cross sections and the fluctuations were almost symmetrically distributed around the center point (the seventh measuring point). The values of mean microhardness and microhardness difference of the wires annealed at $450{ }^{\circ} \mathrm{C}$ for 0,5 , and 60 min were measured of (540 and $26 \mathrm{HV}),(546$ and $49 \mathrm{HV}$ ), and (502 and $25 \mathrm{HV}$ ), respectively (Figure 3a). Figure 3b shows the mean microhardness and microhardness difference of wires annealed for all ranges of time.
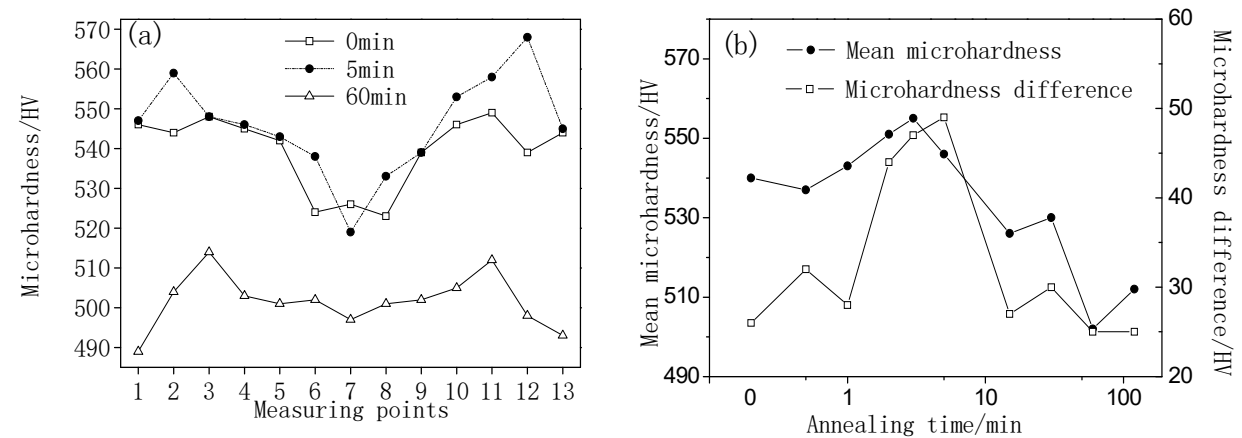

Figure 3. Microhardness of steel wires after annealing at $450{ }^{\circ} \mathrm{C}$ for different time: (a) mean microhardness at different measuring points of wires annealed for 0 , 5, and $60 \mathrm{~min}$; (b) mean microhardness and microhardness difference of wires annealed for the entire time range. 
It is evident from Figures 1 and $3 b$ that the change in mean microhardness was consistent with that of the tensile strength. Microhardness reached its peak value after about 3 min of annealing and then decreased sharply with increasing holding time. However, the variation in microhardness difference was opposite to that of torsion laps. With the prolonged hold time, the microhardness difference first increased and then decreased. The holding time range of 2-5 min with a high microhardness difference coincided with the range of low torsion laps. Further, as the annealing time increased, an inverse relationship was observed between microhardness difference and torsional lap. When the microhardness difference exceeded $40 \mathrm{HV}$, the torsion lap of the wires was less than three circles, and the corresponding torsional fracture was dominated by longitudinal brittle delamination.

\subsection{Microstructure}

Figure 4 exhibits the TEM images of the cold-drawn steel wires before and after annealing. It is noticeable from Figure $4 \mathrm{a}$ that cementites (in lamellar pearlites) maintained a continuous flat structure in the cold-drawn steel wires; however, the flatness of cementites decreased and partial lamellar cementites became discontinuous after 5 min of annealing (Figure 4b). As the annealing time was extended to $15 \mathrm{~min}$, a large area of cementite sheets ruptured, the lamellar structure was damaged significantly, and some nanoscale cementite particles re-precipitated (shown in the ring area of Figure 4c).
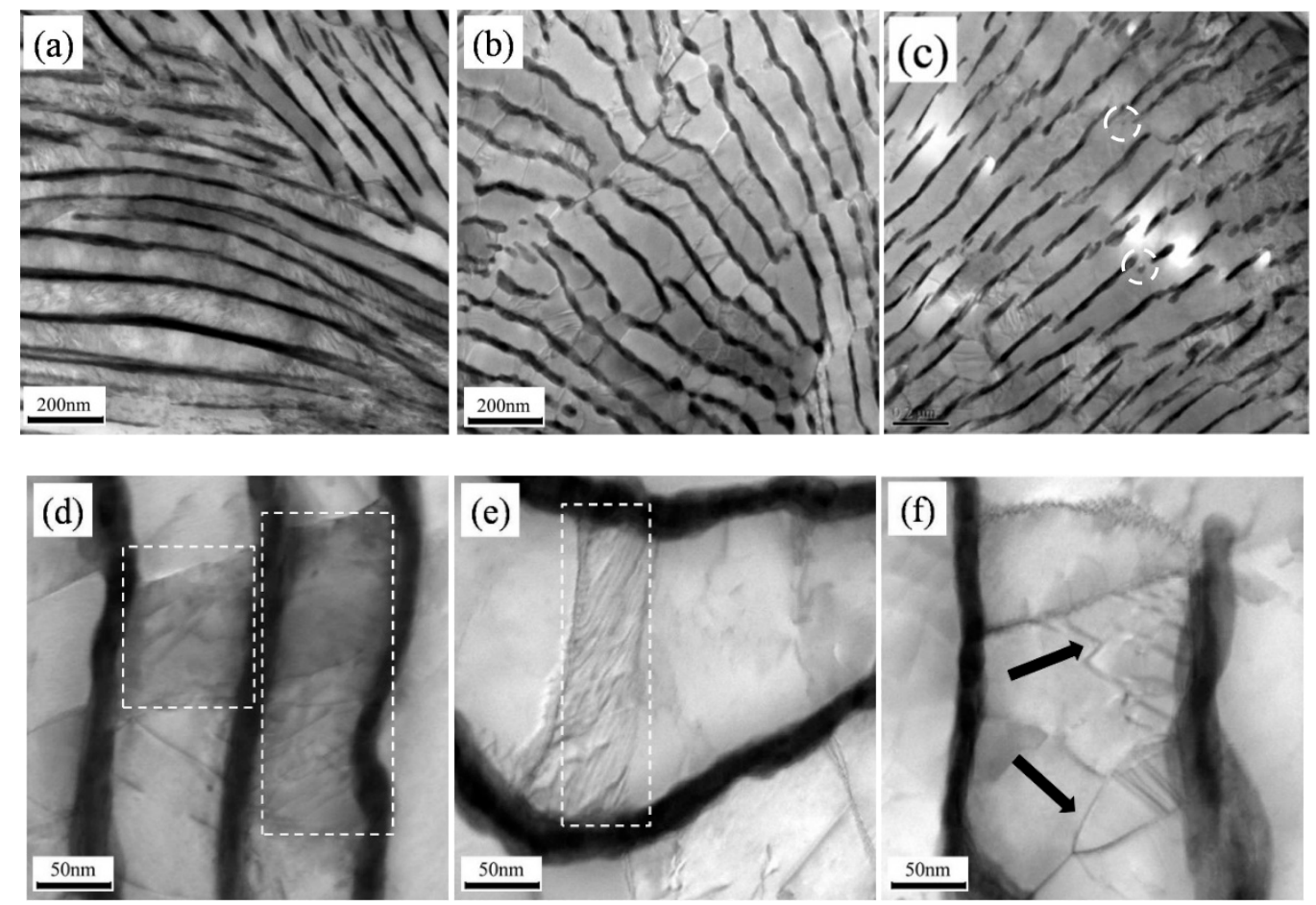

Figure 4. Typical TEM micrographs acquired at the cross-sections of wires: (a,d) cold-drawn wires, surface; (b,e) cold-drawn wires annealed at $450^{\circ} \mathrm{C}$ for $5 \mathrm{~min}$; (c,f) cold-drawn wires annealed at $450{ }^{\circ} \mathrm{C}$ for $15 \mathrm{~min}$.

The dislocation morphologies of pearlites are different from those of single-phase metals. Due to the existence of hard cementites in pearlites, the dislocation structure cannot form a closed loop, thus both ends of the dislocation line are limited by the $\mathrm{F} / \mathrm{Fe}_{3} \mathrm{C}$ interface. In steel wires, the pearlitic interlamellar spacing decreases due to deformation, thus single dislocations cannot be observed. The change in dislocation density can only be detected through TEM [19]. By comparing the dislocation morphologies in ferrites of each sample, it is clear that the distribution of dislocations in ferrites of the cold-drawn wires was dispersive and intertwined (shown in the rectangular area of Figure $4 \mathrm{~d}$ ). With 
the prolonged annealing time, the degree of dislocation motion increased; hence, dislocations merged with each other and were redistributed into a relatively stable sub-grain boundary or line (shown by rectangles or arrows in Figure 4e,f).

The torsion lap of the cold-drawn pearlitic steel wires significantly decreased after annealing at $450{ }^{\circ} \mathrm{C}$ for $2-5 \mathrm{~min}$. It is discernible from Figure 4 that at the initial stage of annealing (2-5 min), the microstructural evolution was accompanied by the following processes: the movement and merging of high-density dislocations in ferrites, the slight dissolution of cementites, and the re-precipitation of diffused carbon atoms. The strength of the steel wires fluctuated slightly due to dislocation motion; however, it remained at a high level because of the presence of unbroken cementite sheets.

Figure 5 exhibits SEM micrographs of the cold-drawn steel wires before and after annealing at $450{ }^{\circ} \mathrm{C}$ for $5 \mathrm{~min}$. Continuous lamellar deformed pearlitic structures (in which ferrites and cementites were alternately arranged) were observed on the surface as well as at the center of the wire without annealing (Figure 5a,b). No spheroidization characteristics were observed in the microstructure, and the torsion lap of the corresponding sample was 17 circles.
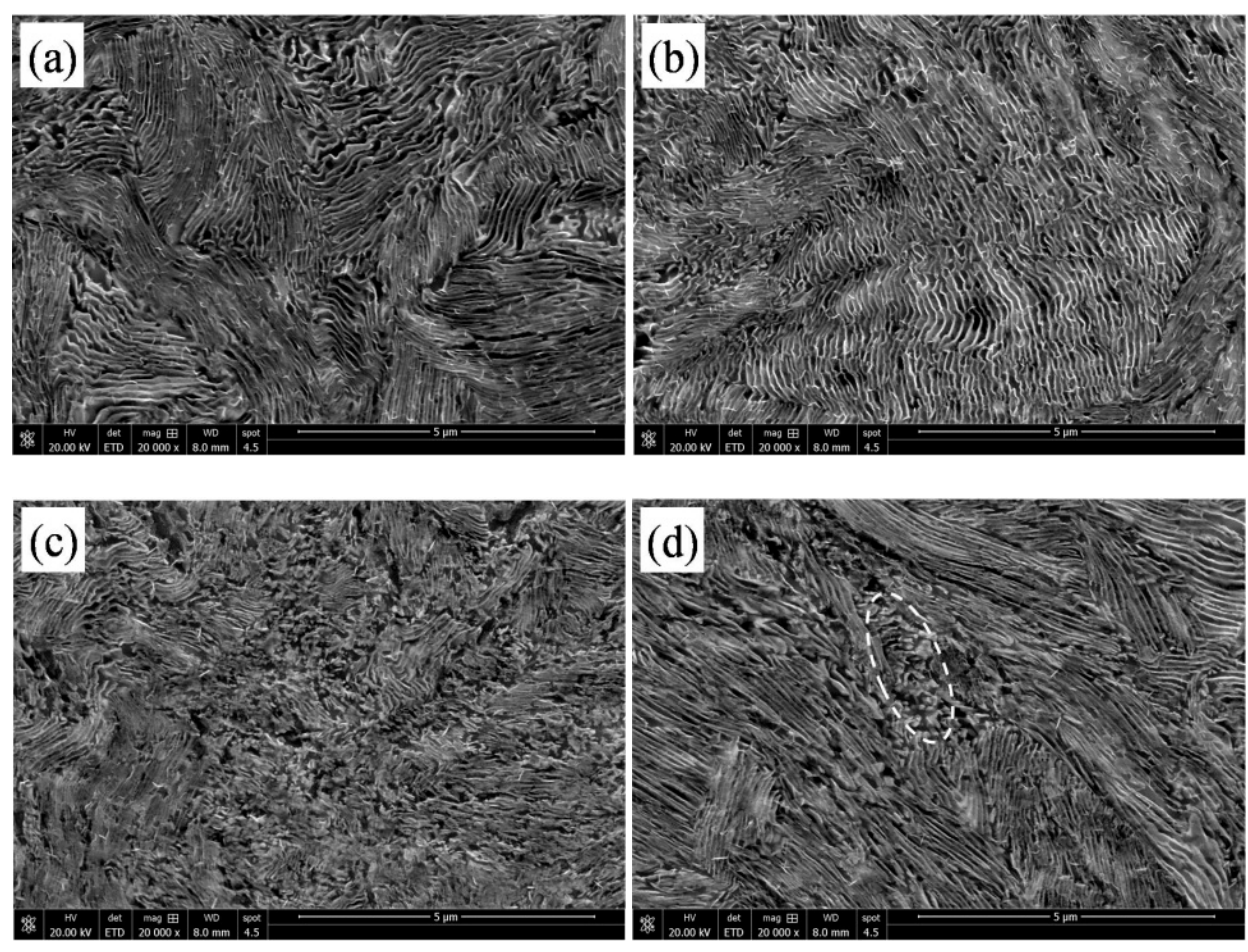

Figure 5. SEM micrographs acquired from the cross section of steel wires: (a) cold-drawn wires, surface; (b) cold-drawn wires, center; (c) cold-drawn wires annealed at $450^{\circ} \mathrm{C}$ for $5 \mathrm{~min}$, surface; (d) cold-drawn wires annealed at $450{ }^{\circ} \mathrm{C}$ for $5 \mathrm{~min}$, center.

The lamellar pearlitic structure was damaged significantly during annealing (Figure $5 c, d$ ). The lengths of lamellar pearlites were reduced, thus lamellar cementites were degraded gradually into short rods or granules. It is evident from Figure $5 c, d$ that the degree of microstructure degradation on the surface was inconsistent with that at the center. A large area of non-lamellar structures was observed on the surface, whereas a small amount of non-lamellar structure appeared at the pearlite boundaries (shown in the ring area of Figure $5 \mathrm{~d}$ ). Therefore, a conspicuous microstructural difference was noticed between the surface and the center of the annealed wire, and the torsion lap of the corresponding sample was only two circles.

The graphical quantitative statistics of the non-lamellar pearlitic structure for each specimen are illustrated in Figure 6. With annealing time exceeding $10 \mathrm{~min}$, the degradation degree of pearlite both in the surface and center of the wires increased, while the difference in degraded degree reduced, 
which led to the decrease in hardness difference and the improvement in torsion laps. However, the strength of wires decreased continually due to the disintegration of lamellar pearlite. The degree of microstructure degradation on the surface was always found to be greater than that at the center. Moreover, the degradation difference between the surface and the center increased at the initial stage of annealing (2-5 $\mathrm{min}$ ) and then gradually decreased with the prolonged holding time. It was also found that when the proportion of non-lamellar structure between the surface and the center exceeded $8 \%$, the microhardness difference was greater than $40 \mathrm{HV}$ and the torsion lap was less than three circles. This phenomenon indicates that the microstructural difference between the surface and the center was the main reason for the decrease in torsion lap.

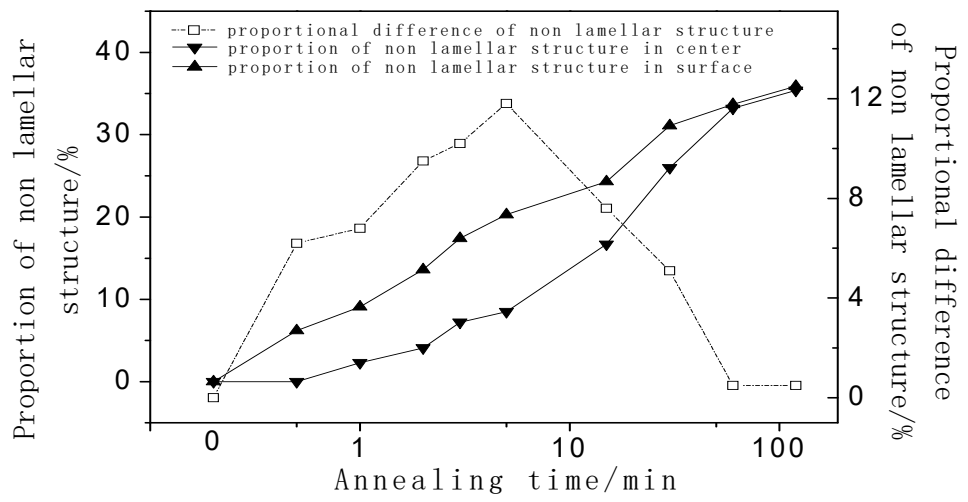

Figure 6. Proportion of non-lamellar structure on the surface and in the center of each specimen.

The microstructural difference between the surface and the center caused stress concentration during the torsion test [13], and consequently led to longitudinal brittle delamination. Voids formed on cementite surfaces [7], and the considerable difference between the maximum and the minimum values of carbon concentration in lamellar ferrites was detected as the main source of stress concentration [20]. The larger surface deformations during the cold-drawing process caused the profound microstructural difference between the surface and the center of the cold-drawn steel wires. Furthermore, the surface layer was heated significantly during the annealing process, thus resulting in large residual stresses [21,22]. Therefore, the evolution of residual stress states is another possible factor for the microstructural difference between the surface and the center of the cold-drawn steel wires.

The main mechanical properties requirement of galvanized steel wires studied in this paper are tensile strength (>2000 MPa) and torsion (>12 circles). According to the variation of the properties with annealing time in Figure 1a, the comprehensive properties of the wires after holding only for 0.5 and 1 min can meet the requirements, and it is not feasible to achieve the matching of strength and torsion laps by prolonging the holding time. In addition, the galvanizing time of wires cannot be reduced in the actual production to ensure its corrosion resistance. Based on the test data, it is anticipated that the torsion laps of galvanized steel wires can be improved on the basis of guaranteeing their strength through two strategies: 1) reducing the heating degree of cold-drawn steel wires in the hot-dip galvanizing process to delaying the degradation and decomposition of lamellar pearlite; 2) reducing the pearlite degradation difference between the surface and center of wires during heating, and ensuring the microstructural similarity between the surface and center of wires.

\section{Conclusions}

The relationship between microstructural evolution and mechanical properties of $2000 \mathrm{MPa}$ cold-drawn pearlitic steel wires during galvanizing simulated annealing was studied experimentally. In addition, reasons for the deterioration in torsional performance of the wires during annealing were investigated. The main inferences are depicted below. 
1. The strength and the microhardness of the wires continued to decrease with the prolonged holding time during annealing at $450{ }^{\circ} \mathrm{C}$. Torsion laps of the wires first decreased and then increased, thus the holding time range of $2-5 \mathrm{~min}$ with a high microhardness difference coincided with the range of low-torsion laps. It is not feasible to achieve the matching of strength and torsion laps by prolonging the holding time for $2000 \mathrm{MPa}$ cold-drawn pearlitic steel wires analyzed in this paper.

2. The microstructural evolution of the steel wires during annealing was accompanied by the following processes: the merging of high-density dislocations, the partial degradation of lamellar pearlites due to the diffusion of dissolved carbon atoms in ferrites, the spheroidization of lamellar cementites, and the re-precipitation of fine cementite particles.

3. The inconsistent microstructure degradation degree of the lamellar pearlitic structure (caused by inhomogeneous deformation and heating) between the surface and the center of the wires was the main reason for the deterioration in torsional performance. When the proportion of non-lamellar structure between the surface and the center exceeded $8 \%$, the microhardness difference was greater than $40 \mathrm{HV}$ and the torsion lap was less than three circles.

Funding: This research was founded by the National Key Research and Development Program of China (grant no. 2017YFB0304800).

Acknowledgments: The author thanks Zhaojun Deng for assistance in TEM analysis.

Conflicts of Interest: The author declares no conflict of interest.

\section{References}

1. Borchers, C.; Kirchheim, R. Cold-drawn Pearlitic Steel Wires. Prog. Mater. Sci. 2016, 82, 405-444. [CrossRef]

2. Goto, S.; Kirchheim, R.; Al-Kassab, T.; Borchers, C. Application of Cold-drawn Lamellar Microstructure for Developing Ultra-high Strength Wires. Trans. Nonferrous Met. Soc. China 2007, 17, 1129-1138. [CrossRef]

3. Zhang, X.; Godfrey, A.; Hansen, N.; Huang, X.X. Hierarchical Structures in Cold-drawn Pearlitic Steel Wire. Acta Mater. 2013, 61, 4898-4909. [CrossRef]

4. Park, D.B.; Lee, J.W.; Lee, Y.S.; Park, K.T.; Nam, W.J. Effect of the Annealing Temperature and Time on the Microstructural Evolution and Corresponding the Mechanical Properties of Cold-drawn Steel Wires. Met. Mater. Int. 2008, 14, 59-64.

5. Fang, F.; Hu, J.; Chen, S.H.; Xie, Z.H.; Jiang, J.Q. Revealing Microstructural and Mechanical Characteristics of Cold-drawn Pearlitic Steel Wires undergoing Simulated Galvanization Treatment. Mater. Sci. Eng. A 2012, 547, 51-54. [CrossRef]

6. Zhou, L.C.; Fang, F.; Zhou, F.; Tu, Y.Y.; Xie, Z.H.; Jiang, J.Q. Cementite Nano-crystallization in Cold-drawn Pearlitic Wires Instigated by Low Temperature Annealing. Scr. Mater. 2016, 120, 5-8. [CrossRef]

7. Lee, J.W.; Lee, J.C.; Lee, Y.S.; Park, K.T.; Nam, W.J. Effects of Post-deformation Annealing Conditions on the Behavior of Lamellar Cementite and the Occurrence of Delamination in Cold-drawn Steel Wires. J. Mater. Process. Technol. 2009, 209, 5300-5304. [CrossRef]

8. Lamontagnea, A.; Massardiera, V.; Klebera, X.; Sauvage, X.; Mari, D. Comparative Study and Quantification of Cementite Decomposition in Heavily Drawn Pearlitic Steel Wires. Mater. Sci. Eng. A 2015, 644, 105-113. [CrossRef]

9. Languillaum, J.; Kapelaki, G.; Baudelet, B. Cementite Dissolution in Heavily Cold-drawn Pearlite Steel Wires. Acta Mater. 1997, 45, 1201-1212. [CrossRef]

10. Gridnev, V.N.; Gavrilyuk, V.G.; Dekhtyar, I.Y.; Meshkov, Y.Y.; Nizin, P.S.; Prokopenko, V.G. Investigation of Carbide Phase in Strained Steel by the Method of Nuclear Gamma Resonance. Phys. Status Solidi A 1972, 14, 689-694. [CrossRef]

11. Watte, P.; Humbeeck, J.V.; Aernoudt, E.; Lefever, I. Strain Ageing in Heavily Drawn Eutectoid Steel Wires. Scr. Mater. 1996, 34, 85-95. [CrossRef]

12. Brandaleze, E. Structural Evolution of Pearlite in Steels with Different Carbon Content under Drastic Deformation during Cold Drawing. Procedia Mater. Sci. 2015, 8, 1023-1030. [CrossRef] 
13. Zhou, L.C.; Fang, F.; Wang, L.; Chen, H.Q.; Xie, Z.H.; Jiang, J.Q. Torsion Delamination and Recrystallized Cementite of Heavy Drawing Pearlitic Wires After Low Temperature Annealing. Mater. Sci. Eng. A 2018, 713, 52-60. [CrossRef]

14. Tanaka, M.; Saito, H.; Yasumaru, M.; Higashida, K. Nature of Delamination Cracks in Pearlitic Steels. Scr. Mater. 2016, 112, 32-36. [CrossRef]

15. Tarui, T.; Maruyama, N. Effect of Cementite Decomposition on Delamination in High Carbon Steel Wires. J. Iron Steel Inst. Jpn. 2004, 90, 1031-1037. [CrossRef]

16. Jaya, B.N.; Goto, S.; Richter, G.; Kirchlechner, C.; Dehm, G. Fracture Behavior of Nanostructured Heavily Cold-drawn Pearlitic Steel Wires before and after Annealing. Mater. Sci. Eng. A 2017, 707, 164-171. [CrossRef]

17. Lee, S.K.; Ko, D.C.; Kim, B.M. Pass Schedule of Wire Drawing Process to Prevent Delamination for High Strength Steel Cord Wire. Mater. Des. 2009, 30, 2919-2927. [CrossRef]

18. Zelin, M. Microstructure evolution in pearlitic steels during wire drawing. Acta Mater. 2002, 50, 4431-4447. [CrossRef]

19. Bae, C.M.; Nam, W.J.; Lee, C.S. Effect of microstructural features on ductility in hypo-eutectoid steels. Scr. Mater. 1999, 41, 605-610. [CrossRef]

20. Hong, M.H.; Reynolds, W.T.; Tarui, T.; Hono, K. Atom probe and transmission electron microscopy investigations of heavily drawn pearlitic steel wire. Metall. Mater. Trans. A 1999, 30, 717-727. [CrossRef]

21. Kumagai, M.; Sato, S.; Suzuki, S.; Imafuku, M.; Tashiro, H.; Ohya, S.I. Residual Stress Analysis of Cold-drawn Pearlite Steel Wire UsingWhite Synchrotron Radiation. ISIJ Int. 2015, 55, 1489-1495. [CrossRef]

22. Toribio, J.; Lorenzo, M.; Vergara, D.; Aguado, L. Residual stress redistribution induced by fatigue in cold-drawn prestressing steel wires. Constr. Build. Mater. 2016, 114, 317-322. [CrossRef]

(C) 2019 by the author. Licensee MDPI, Basel, Switzerland. This article is an open access article distributed under the terms and conditions of the Creative Commons Attribution (CC BY) license (http:/ / creativecommons.org/licenses/by/4.0/). 